\title{
Evaluation of antibody titers of Noiler chickens fed with different biotic additives against Newcastle disease
}

"Idowu, K. R., ${ }^{2}$ Adeyemi, O. A., ${ }^{3}$ Oni, O. O. and ${ }^{4}$ Sogunle, O. M.

Department of Animal Production and Health ${ }^{1,2 \& 4}$, Department of Veterinary Medicine ${ }^{3}$

University of Agriculture, P.M.B. 2240, Abeokuta, Nigeria.

Corresponding author: feramoo@yahoo.com; idowukr@funaab.edu.ng; $+2347039394758$

\section{Abstract}

Immunity plays a key role in maintaining animal health, and thereby helps to enhance performance in livestock. The focus of alternative antibiotic growth promoters (prebiotic, probiotic, and symbiotic) strategies has been to prevent proliferation of pathogenic pathogen and to improve the immune status and performance of livestock. A total of 360, day old Noiler chickens were randomly distributed into 12 treatments with 3 replicates of 10 birds each. Experimental treatments consisted of 4 different growth promoters (probiotic, prebiotic, symbiotic and antibiotic) at 3 inclusion rates (0, 0.5 and $1 \mathrm{~g})$ into $\mathrm{kg}$ of feed respectively. The chickens were reared for a period of 42 days to evaluate the titer value of the bird fed with different growth promoters (prebiotic, probiotic, symbiotic and oxytetracycline antibiotic). The results obtained revealed significant differences in $(P<0.05)$ in the Newcastle disease titer value of birds fed with different growth promoters with prebiotic having the best value (4.67), followed by symbiotic (4.55) and the inclusion of growth promoters at $1 \mathrm{~g}$ into a $\mathrm{kg}$ of feed were significantly improved for prebiotic (6.00) and symbiotic (5.60) as compared to 0.5 and $0 \mathrm{~g}$ level of inclusion across the biotic additives. Hence it could be concluded that inclusion of prebiotic improved the Newcastle disease titer value of Noiler chicken at $1 \mathrm{~g} / \mathrm{kg}$ of feed.

Keywords: Noiler, titer value, prebiotic, probiotic, additives

\section{Introduction}

Disease has always been a critical issue in livestock production, affecting not only animal health and well-being, but also the physical and economic health of the producer (Patterson et al., 2003). The focus of alternative antibiotic growth promoters (prebiotic, probiotic, and symbiotic) strategies have been to prevent proliferation of pathogenic bacteria and modulation of indigenous bacteria so that the health, immune status and performance of livestock are improved (FAO, 2001). Objective of this study is the use of natural biotic additives to enhance the immune system as a replacement of antibiotic growth promoter in poultry production to produce wholesome animal products. Gibson and Roberfroid (1995), defined probiotic as natural intestinal bacteria that, after oral administration in effective doses, are able to colonize the animal digestive tract, thus keeping or increasing the natural flora, preventing colonization of pathogenic organisms and securing optimal utility of the feed. On the other hand, prebiotics are defined as non-digestible food ingredients that affect the host beneficial by selectively stimulating the growth and/or activity of bacteria in the colon (Gibson and Roberfroid, 1995). However, the combinations of prebiotic and probiotic are referred to as symbiotic. There is an increasing interest in finding alternate growth promoters being able to restore a healthy microbial flora and/or prevent the uncontrolled growth of unwanted microorganisms. Immunity plays a key role in maintenance of health status of animal, and for production of maximal performance in livestock. It is therefore, necessary to enhance the immune status of animal to 


\section{Evaluation of antibody titers of Noiler chickens}

reduce profit loss and wholesome animal produce. Rolfe (2000) reported that, one of the goals of the poultry industry is to enhance the immune system of farm animal for production of wholesome animal products. The concerns about harmful side effects caused by antibiotics (Lopez., 2000) has grown in many countries, so that there is an increasing interest in finding alternatives to antibiotics in poultry production. Probiotics, prebiotics and symbiotics have provided a possible natural alternative to antibiotics in poultry production to produce foods of reliable quality and safety.

\section{Materials and methods Test ingredient profile}

The prebiotic used was Manna oligosaccharides (MOS); the probiotics used for this experiment was "Primilac" which contained Enterococci faecium, Bacillus species, Bifidobacterium bifidum, and yeast Saccharomyces cerevisiae, and the Synbiotic "Biotin ${ }^{\otimes}$ which contained Enterococci faecium, Bacillus species, Bifidobacterium bifidum, and the yeast (Saccharomyces cerevisiae), sea weed, and amylase as the active ingredients while the antibiotic was oxytetracycline hydrochloride.

\section{Animal management}

Three hundred and sixty day old Noiler chicks were acquired from Amo farm Sieberer hatchery limited in Awe, Oyo State for this experiment. The birds were randomly distributed into 12 treatments with 3 replicates of 10 birds each. Experimental treatments consisted of 4 different growth promoters (probiotic, prebiotic, symbiotic and antibiotic) at 3 inclusion rates $(0,0.5$ and $1 \mathrm{~g})$ into $\mathrm{kg}$ of feed respectively. The experiment commenced on the bird's arrival and the chicks were placed on these for a period of six weeks representing the chick phase.

Prior to the arrival of the birds, the poultry house was thoroughly cleaned and disinfected. The feeders and drinkers were kept clean. Feed and water were made available to the birds ad libitum. On arrival, the birds were given feed containing probiotic, prebiotic, symbiotic and antibiotic and these continued throughout the period of the experiment.

\section{Experimental layout}

The experiment was laid out in a $4 \times 3$ factorial arrangement. There were two factors: Biotic additive (prebiotic, probiotic, symbiotic and antibiotic) and level of inclusion $(0,0.5,1 \mathrm{~g} / \mathrm{kg})$ in feed. Data generated were subjected to completely Randomised Design as described by Steel and Torrie (1980). Duncan was employed in comparing differences among treatment means as contained in SAS (2010) statistical package.

Determination of antibody titers against Newcastle disease

For investigation of the humoral immunity, $1 \mathrm{~mL}$ of blood was taken vial the jugular vein from one bird per replicate at day one on arrival for determination of maternally derived antibody titer. Also, on days 21 and 39 blood sample were collected. First blood samplings were collected on day 1 of age before vaccination of $B_{1}$ Newcastle disease to determine the similarity of parent stock titre. The second and third time of blood sampling were collected at 1 week after $1^{\text {st }}$ and $2^{\text {nd }}$ vaccination with Newcastle disease vaccines to measure the titer level. The blood samples collected were allowed to stand for 30 minutes for sera formation, after which the sera were collected in ependorf tubes. Haemaglutination and Haemaglutination inhibition tests were used to evaluate the antibody concentration against Newcastle disease virus using micro-titer method. Lasota vaccine was used as the source of antigen, serum antibodies titers of these chickens was determined against Newcastle disease vaccine by humoral immunity of 
Hemagglutination Inhibition (HI) test. All samples of blood were justified by serologic procedure hemagglutination

control test. Table 2 shows the vaccination regime that was used for Noiler chicken.

Table 1: Percentage composition of Noiler starter diet

\begin{tabular}{|c|c|}
\hline Ingredients & Composition (\%) \\
\hline Maize & 50.00 \\
\hline Soybean meal & 21.00 \\
\hline Wheat offal & 12.00 \\
\hline Groundnut cake & 10.00 \\
\hline Fish meal $(72 \% \mathrm{CP})$ & 2.00 \\
\hline Bone meal & 2.50 \\
\hline Oyster shell & 1.50 \\
\hline *Vitamin and Mineral premix & 0.25 \\
\hline Lysine & 0.25 \\
\hline Methionine & 0.25 \\
\hline Salt $(\mathrm{NaCl})$ & 0.25 \\
\hline TOTAL & 100.00 \\
\hline Crude protein $(\%)$ & 23.35 \\
\hline Crude fiber $(\%)$ & 3.40 \\
\hline Ether extracts $(\%)$ & 3.32 \\
\hline $\mathrm{Cal}(\%)$ & 1.32 \\
\hline $\mathrm{ME}(\mathrm{Kcal} / \mathrm{kg})$ & 2822.38 \\
\hline \multicolumn{2}{|l|}{ Determined Analysis } \\
\hline Dry matter & 89.63 \\
\hline Crude protein & 22.94 \\
\hline Crude fiber & 3.84 \\
\hline Ether extract & 3.56 \\
\hline Ash & 5.20 \\
\hline
\end{tabular}

Table 2: Vaccination regime for Noilers

\begin{tabular}{ll}
\hline Age & Vaccination \\
\hline Day 1 & Marek's \\
Day 8 & IBDV-(Initial dose) \\
Day 14 & NDV-Lasota Strain \\
Day 17 & IBDV (Booster dose) \\
Day 32 & NDV-(Booster dose) \\
\hline
\end{tabular}




\section{Evaluation of antibody titers of Noiler chickens}

\section{Results}

Main effect of different biotic inclusion on Newcastle disease titer value of Noiler chicken

The results of the main effect of different biotic additive on Newcastle disease titer value of Noiler chicken are presented in Table 3. Inclusion of different biotic significantly affected the titer value at the second collection period but the values were not significantly improved. The third collection significantly improved the titer values with prebiotic (4.67) and symbiotic (4.55) biotic treatments significantly $(\mathrm{P}<0.05)$ higher in birds that were fed probiotic (4.10) and antibiotic (4.00) biotic diets respectively.

Table 3: Main effect of different biotic additive on Newcastle disease titer value of Noiler chicken

\begin{tabular}{llllllllll}
\hline Parameters & \multicolumn{3}{c}{ Biotic Additive } & \multicolumn{5}{c}{ Levels of biotic Inclusion $(\mathrm{g} / \mathrm{kg})$} \\
\hline Period & Prebiotic & Probiotic & Synbiotic & Antibiotic & SEM & 0 & 0.5 & 1 & SEM \\
\cline { 2 - 8 } $1^{\text {st }}$ & 4.78 & 5.33 & 5.00 & 5.11 & 0.5 & 4.83 & 5.25 & 5.08 & 0.55 \\
$2^{\text {nd }}$ & $3.30^{\mathrm{a}}$ & $2.33^{\mathrm{b}}$ & $1.89^{\mathrm{c}}$ & $1.89^{\mathrm{c}}$ & 1.1 & 2.41 & 2.33 & 2.33 & 1.13 \\
$3^{\text {rd }}$ & $4.67^{\mathrm{a}}$ & $4.10^{\mathrm{b}}$ & $4.55^{\mathrm{a}}$ & $4.00^{\mathrm{b}}$ & 0.25 & $3.75^{\mathrm{c}}$ & $4.16^{\mathrm{b}}$ & $5.05^{\mathrm{a}}$ & 0.25 \\
\hline \multicolumn{6}{c}{ a,b,c, Means in the same row not sharing common superscript are significantly different $(\mathrm{p}<0.05)$ SEM: Standard } \\
Error mean
\end{tabular}

Interactive effect of different biotic inclusion on Newcastle disease titer value of Noiler chicken

The results of the interaction of different biotic additive on Newcastle titer value of Noiler chicken is shown in Table 4. The results have significant effect on titer value at the second and $3^{\text {rd }}$ immunization. The results of the second vaccination showed that the level of inclusion on titer values were not significantly $(\mathrm{P}>0.05)$ improved. However, the second titer value were significantly $((\mathrm{P}<0.05)$ improved with prebiotic (6.00) having the highest value, followed by symbiotic (5.60) treatments at $1 \mathrm{~g} / \mathrm{kg}$ level of feed inclusion.

Table 4 Interactive Effect of different biotic additive on Newcastle disease titer value of Noiler chicken

\begin{tabular}{lllllllllllllll}
\hline Parameters & \multicolumn{10}{c}{ Biotic Additive } \\
\cline { 2 - 13 } Levels & 0 & 0.5 & 1 & 0 & 0.5 & 1 & 0 & 0.5 & 1 & 0 & 0.5 & 1 & \\
$n^{\text {st }}$ & 5.00 & 4.66 & 4.66 & 4.66 & 5.66 & 5.66 & 5.66 & 5.33 & 5.00 & 5.00 & 5.30 & 5.00 & 0.74 \\
$2^{\text {nd }}$ & $3.00^{\mathrm{b}}$ & $2.60^{\mathrm{c}}$ & $4.33^{\mathrm{a}}$ & $3.33^{\mathrm{b}}$ & $2.00^{\mathrm{c}}$ & $1.60^{\mathrm{c}}$ & $1.67^{\mathrm{c}}$ & $1.6^{\mathrm{c}}$ & $2.33^{\mathrm{b}}$ & $1.6^{\mathrm{c}}$ & $3.00^{\mathrm{b}}$ & $1.00^{\mathrm{c}}$ & 1.06 \\
$3^{\text {rd }}$ & $3.00^{\mathrm{e}}$ & $5.00^{\mathrm{b}}$ & $6.00^{\mathrm{a}}$ & $4.00^{\mathrm{d}}$ & $4.00^{\mathrm{d}}$ & $4.30^{\mathrm{c}}$ & $4.00^{\mathrm{d}}$ & $4.00^{\mathrm{d}}$ & $5.60^{\mathrm{b}}$ & $4.00^{\mathrm{d}}$ & $3.60^{\mathrm{d}}$ & $4.30^{\mathrm{c}}$ & 0.50 \\
\hline a,b,c, Means in the same row not sharing common superscript are significantly different $(\mathrm{p}<0.05)$ SEM: Standard \\
Error mean
\end{tabular}

\section{Discussion}

Immunity in Poultry is a comprehensive aspect that involves different aspect of organs and cells in their body. The entire system is a combination of network of cells and organs that are responsible for different functions. At second day, before the chickens' vaccination, the averages of analysed result of antibody titer on Table 3 were considered passive antibodies (maternal origin) as a result of this the higher antibody titer reported were maternal antibodies which reduces gradually after the chicks had been hatched. Innate immunity is often not able to fight off the pathogen and prevent disease. At 


\section{Idowu, Adeyemi, Oni and Sogunle}

this point adaptive immunity is required to specifically focus on defense mechanisms on that particular pathogen resulting not only in the elimination of the pathogen but also as protection in case of a repeat encounter with the same pathogen. It is the ability of adaptive immunity to recognize molecular features of the pathogen using highly specific antigen receptor-antigen interactions that conveys specificity to adaptive immunity and allows it to specifically focus on immune activities on the invading pathogen At 28 days old a week after the first vaccination across the entire treatments the titre value were not significantly improved, although prebiotic has the highest titer value followed by probiotic but these are below the recommended value. At 39 days old the biotic treatment significantly improved the titer across the dietary treatments. Prebiotic treatment emerged as the best followed by the treatment that were fed symbiotic additive and subsequently probiotic and antibiotic respectively, this work is in line with Afshin and Pedimk (2011) who reported improved humeral immunity titre for broiler that were fed Prebiotic (MOS). Vaccination programs in Chicken is basically to improve the titer value of antigen-specific cells for production of antigen-specific memory cells, whereby a non-pathogenic form of a pathogen is introduced to the chicken's immune system to produce antibody which later respond to the pathogenic type of the pathogen against the disease outbreak. The inclusion of probiotic and symbiotic additives at $1 \mathrm{~g} / \mathrm{kg}$ level of inclusion recorded a better titre value likewise the birds on treatment that contained prebiotic additive at $0.5 \mathrm{~g} / \mathrm{kg}$ of feed. Muraroll (2014) and Zulkifli et al. (2000), reported a similar report when evaluating antibody titres against Newcastle disease. They observed higher titers values in treatments with probiotic compared to antibiotics. Afshin and
Pedimk (2011) reported a similar improved humeral immunity titre for broiler that were fed Prebiotic (MOS).

\section{Conclusion}

The study showed that the treatment that contained prebiotic recorded an improved Newcastle disease titer value at day (36) of age as compared with other treatments that contained probiotic, symbiotic and antibiotic respectively, likewise the inclusion of Prebiotic at $1 \mathrm{~g} / \mathrm{kg}$ of feed improved the Newcastle disease titer level comparatively to 0 and $0.5 \mathrm{~g}$ inclusion level. Prebiotic (Mannaoligoshaccarides) are dietary components which are not digested in the gastrointestinal tract, but stimulate the growth and enhance the health status of animal. Some herbs and plants are good prebiotics which can improve and enhance the immune and health of livestock. Conclusion could be drawn from this experiment that (MOS) improved the immune status of Noiler chickens vaccinated with Newcastle disease vaccine.

\section{References}

Food and Agriculture Organization and World Health Organization, 2001. Report of a Joint FAO/WHO Expert Consultation on Evaluation of Health and Nutritional Properties of Probiotics in Food Including Powder Milk with Live Lactic Acid Bacteria.

Gibson, G. R. and Roberfroid, M. B. 1995. Dietary modulation of the human colonic microbiota: introducing the concept of prebiotics. Journal Nutraceuticals. 125:1401-1412

Hajati, H. and Rezaei, M. 2010. The Application of Prebiotics in Poultry. International Journal of Poultry Science, 9 (3), Pg 298-304

Murarolli, V. D. A., Burbarelli, M. F. C., Polycarpo, G. V., Ribeiro, P. A. P., 


\section{Evaluation of antibody titers of Noiler chickens}

Moro, M. E. G. and Albuquerque R. 2014 Prebiotic, probiotic and synbiotic as alternative to Antibiotics on the Performance and Immune Response of Broiler Chickens Rev. Bras. Cienc. Avic. vol.16 no. 3

Patterson, J. A. Burkholder K. M. 2003. Application of Prebiotics and Probiotics in Poultry Production Poultry. Science. 82 Pg. 627-631

SAS, 2010. Users statistics. Statistical Analyses System Institute Inc. Cary,NC, USA.

Sebastian, S., Touchburn, S. P., Chavez, E. R. and Lague, P. C. 1997. Apparent digestibility of Protein and amino acids in broiler chickens fed a corn-soybean diet supplemented with microbial phytase. Poultry Science.,76: Pg. 1760-1769.
Zulkifli, I., Abdullah, N., Azrin, N. M. and Ho, Y. W. 2000. Growth performance and immune response of two commercial broiler strains fed diets containing Lactobacillus cultures and oxytetracycline under heat stress conditions. British Poultry Science 2000; 41, Pg 593597.

Received: $14^{\text {th }}$ November, 2019 Accepted: $29^{\text {th }}$ February, 2020 